\title{
José María Eguren y la búSQueda de la PROPIA ESENCIA: UN POETA MÁS ALLÁ DEL MODERNISMO Y DEL POSTMODERNISMO
}

\author{
Ainhoa Segura Zariquiegui \\ Universidad de Burgos
}

\section{RESUMEN:}

Muchos de los genios, tanto de la literatura como de cualquier otra área artística, son difíciles de clasificar. Esto es debido a que su expresión creativa es demasiado novedosa y los cánones establecidos no encuentran un lugar para ella. José María Eguren dejó perplejos a los críticos de su época. La poesía egureniana se encontraba más allá del Modernismo e incluso del Posmodernismo porque era una poesía que expresaba la esencia íntima del autor. En este artículo se va a examinar esta cuestión. A través de este análisis de varios de sus poemas se podrán observar las características estilísticas que hacen de Eguren un autor inclasificable y único.

\section{PALABRAS CLAVE:}

literatura; poesía; Modernismo; Eguren.

\begin{abstract}
:
Many of genial artists, in literature and other artistic areas, are difficult to classify because their creative expression is too new. Jose María Eguren suprised the critics; they did not know where framing his poetry. The Eguren poetry was beyond Modernism and Postmodernism. The Eguren poetry was a poetry that expresed the essence of the autor. This article is going to discuss this issue. Througt the analysis of several poems, we can observe the stylistic features that make this poet as a unique autor.
\end{abstract}

\section{KEYWORDS:}

Key words: literature; poetry; Modernism; Eguren.

José María Eguren nació en Lima (1874-1942) y está considerado como uno de los fundadores de la poesía peruana moderna. Publicó dos poemarios titulados Simbólicas (1911) y La canción de las figuras (1916). En 1931 apareció Motivos, obra donde se encuentran muchos de los artículos que habían sido publicados en diversas revistas que trataban sobre diferentes temas relacionados casi siempre con el arte y la belleza (Valles, 2016). El vate peruano se vio, en cierta manera, influido por algunos poetas extranjeros: «Eguren recibió la influencia, aunque no los leyera, de Rimbaud y Mallarmé y definitivamente de Verlaine que sí le fue familiar. Muy gravitante fue la figura de Edgar Allan Poe y su teoría poética de recoger la emoción 
del poema de modo condensado». ${ }^{.}$Pero, aunque posee influjos de corte muy variado, la escritura de Eguren toma distancia con el Simbolismo decadente francés y con la estética de Poe. Llega, incluso, a escapar del Modernismo rubendariano y huye del tono modernista peruano liderado por Chocano. Igualmente, Mariátegui observa que el posicionamiento estético de este poeta se aleja del indigenismo y hasta de la civilización capitalista:

Eguren, en el Perú, no comprende ni conoce al pueblo. Ignora al indio, lejano de su historia y extraño a su enigma. Es demasiado occidental y extranjero espiritualmente para asimilar el orientalismo indígena. Pero igualmente, Eguren no comprende ni conoce tampoco la civilización capitalista, burguesa, occidental. ${ }^{2}$

La descolocación de los primeros críticos de Eguren como Zulen (1977), Basadre (1928) y también de algunos posteriores como Ferrari (1977), muestra el extrañamiento de la crítica ante esta novedosa poesía. La crítica percibió la extrañeza la singular obra poética de Eguren, pero no supo explicitar qué atrapó sus sentidos: «La poesía de Eguren es, pues, un sistema verbal que busca llegar a lo desconocido, pero que, paradójicamente, revela una distancia en el mismo momento que nos acerca la lejanía». ${ }^{3}$ La poesía del peruano, lejos de ser enunciativa, como lo era la de Chocano, pasa a ser dificultosa: «Eguren sugería -afirma Estuardo Núñez-, pero nadie estaba acostumbrado a que le sugieran donde campeaba un concepto hablativo de la poesía». ${ }^{4}$ El Modernismo peruano, capitaneado por Chocano, con fuerte retoricismo, y grandes y rimbombantes versos, era básicamente enunciativo, se debía entender de una sola vez, en cambio, la poesía de Eguren debía ser meditada, pensada, saboreada porque su encanto radicaba en llevar al lector a un mundo mágico. John Brande Trend señala en la obra compilatoria de Ricardo Silva-Santisteban José María Eguren. Aproximaciones y perspectivas: «Su voz es suave; se horrorizaría ante la idea del verso que se convirtiera en una trompeta». ${ }^{5}$ El mundo de Eguren no es ruidoso, es más bien, insinuante, rumoroso y hechicero.

\footnotetext{
${ }^{1}$ José Antonio González, «Utopías y nacionalismo cultural en América Latina. La interpretación de Andrés Sabella a la contribución de Mariátegui, Vallejo y Eguren», Estudios políticos, 40, pág. 133.

${ }^{2}$ José Carlos Mariátegui, 7 ensayos de la realidad peruana. Lima, Empresa Editora Amauta, 1989, pág. 302.

${ }^{3}$ Josué Chapilliquén, La crisis sacrifical en la poesía de José María Eguren. Lima, Pontificia Universidad Católica de Perú, 2011, pág. 4.

${ }^{4}$ Estuardo Núñez, La poesía de Eguren. Lima, Compañía de Impresiones y Publicidad Editores, 1932, pág. 15.

${ }^{5}$ John Trend, «Perú ignoto», en José María Eguren. Aproximaciones y perspectivas, Lima, Universidad del Pacífico, 1977, págs. 66-67.
} 
José María Eguren y la búsqueda de la propia esencia...

La poesía modernista, tanto peruana como hispanoamericana, había caído en una repetición de lugares comunes impuestos por el talento de Rubén Darío. Eguren reivindica, aun partiendo de los poetas simbolistas franceses, su propia originalidad, la innovación intuitiva, pero desde cánones internos al poeta, desde su mundo interior. Y lo invoca expresando el valor plástico de las palabras que, huyendo de los tópicos modernistas, se adentran en un subjetivismo significativo. La palabra tiene fuerza estética en sí misma: «Hay palabras definitivas en su sonido expresivo como amor, alegría, ternura, mañana, tarde, noche y tantos otros vocablos eufónicos, de significativa justeza -afirma Eguren-. Hay palabras que pronunciadas al acaso despiertan simpatía, hay otras que por su acento y significación producen estremecimiento estético». ${ }^{6}$ Las palabras poseen un valor. No todas proporcionan la imprescindible sugestión que lleva a componer la orquestación de la poesía; hay unas que sí y otras que no. De la palabra, a Eguren sólo le interesa su contenido poético, su valor insinuante y su belleza: «Angustiosamente pretendemos alcanzar la altura canora y anhelamos el diafragma que diga la palabra bella». ${ }^{7}$ Si no existe la palabra deseada para conseguir la sugestión, se busca en el pasado, por medio de arcaísmos o, simplemente, se inventa. La creación literaria de Eguren evoluciona hasta fundar sus propios elementos, puesto que los conocidos no alcanzan a describir el universo poético del artista. El ejemplo de creación de sustantivos lo encontramos a lo largo de sus dos poemarios, pero de una manera condensada en el poema «El pelele». Éste se encuentra armado con palabras que poseen su alma, pero la paleta nominal se queda pequeña, es necesario ampliarla. Si bien, los modernistas utilizaron palabras tomadas de tiempos arcaicos, Eguren lo que hace es moldearlas para ponerlas al servicio del mundo interior del poema impregnándolo todo de palabras «sinestésicas». ${ }^{8}$ El pelele es un muñeco de trapo enamorado de unas perversas y hermosas princesas. Las malignas rodean al pelele y le azotan hasta matarlo. El vocabulario, a veces trágico, otras, cómico, siempre mágico, se integra perfectamente en el ambiente fantasmal:

\footnotetext{
${ }^{6}$ José María Eguren, Obras completas. Lima, Ed. Lima, 1997, pág. 196.

${ }^{7}$ Ibíd. Pág. 95.

${ }^{8} \mathrm{Jim}$ Anchante, Naturaleza y función de los símbolos en el poemario Simbólicas de José María Eguren. Lima, Pontificia Universidad Católica de Perú, 2011, pág. 10.
} 


\begin{abstract}
Las princesas rubias al triste pelele festivas marean en cálida ronda; y loco se duele, veloz acompasa la giba redonda y los cascabeles, la turbia mirada, la nez purpurada.
\end{abstract}

Y comienzan a aparecer palabras jitanjafóricas (pensemos no sólo en el significado, también tiene importancia el sonido). El pelele baja la vista ante la belleza de las crueles princesitas: «en ojos gachones que el amor enciende». El adjetivo elegido dramatiza el cuadro y lo envuelve de un tono teatral con matices guiñolescos; son los ojos que se agachan, son los «ojos gachones». Otro ejemplo: «Las princesas cantan la pelelenía». El pelele tiene un mundo, y una forma característica que lo conforma. Se ha inventado un adjetivo, utilizando el sustantivo existente. En este mismo poema, de dulce, nace dúlcida, y de triste, tristecía. Las metamorfosis nominales ayudan a crear el mundo fantasmagórico en el que el embrujo egureniano nos introduce. Son el vínculo, el lazo, y más que eso, son el anzuelo que nos ayuda a traspasar nuestra realidad e internarnos en un mundo de muecas infantiles, plagado de elementos fantásticos, irreconocibles y agridulces.

Como se comentaba, las palabras son entes artísticos manejables, son herramientas poéticas con alma propia. Y aquí es donde se produce el acercamiento mayor de Eguren con el Simbolismo. Las palabras pintan, cantan y cuentan. La unión de artes plásticas en busca de la sugerencia y la incitación a la sensación, recuerda la teoría de las correspondencias. En el caso de Eguren, el color (que obsesionaba al poeta) impregna de significación la paleta cromática. El poeta peruano, señala Estuardo Núñez: «malabariza con el color, lo saca de donde lógicamente debe estar y lo lleva donde poéticamente quiere ponerlo». ${ }^{9}$ Uno de tantos ejemplos se encuentra en «Las bodas vienesas»: «En la casa de las bagatelas, / vi un mágico verde de rostro cancaño / y las cinderelas / vistosas le cubren la barba de sueño» (Simbólicas). El verde es utilizado para describir la cara del mago. Son colores fuertes a los que recurre el yo poético para destacar valores más profundos de los que percibidos a primera vista. De ahí que el cromatismo aparezca fuera del lugar al que normalmente pertenece y recuerde a las pinturas impresionistas. En el poema «Lied II» (Simbólicas) se describe el emerger de la muerta virgen nacarina del mar. Ésta se encuentra acompañada de un «cuervo incierto» que la guía en «violeta navegar». El color violeta aplicado al verbo navegar da una sensación de profundidad y oscuridad que, al ser empleado en un lugar extraño, le otorga una fuerza de mayor patetismo a la escena poética.

\footnotetext{
${ }^{9}$ Estuardo Núñez, op. cit., pág. 41.
} 
José María Eguren y la búsqueda de la propia esencia...

Como señala J. R. Valles Calatrava (2011), además de la paleta de color, también asimila la musicalidad que aprendió leyendo a Verlaine. Explica Eguren: «Tengo un recuerdo musical que sería una pintura». ${ }^{10} \mathrm{Y}$ continúa detallando: «La música es persuasiva y sugerente; señala vías rosadas y paraísos perlinos; los ensueños, las almas matizadas y los símbolos». ${ }^{11} \mathrm{Si}$ bien, desde la perspectiva simbolista lo más interesante de la obra poética es la sugerencia (que se considera una puerta de entrada a algo nuevo); en Eguren, esta sugerencia se agita con una gran rotundidad y brillantez: «Vamos por la región de lentitudes y de tarde en tarde se nos abre una puerta luminosa. ¿Adónde nos llevará este arte de los misterios sensibles? $\gg^{12}$ Nos lleva a la inmersión de un mundo nuevo, repleto de seres guiñolescamente teatrales y de personajes infantiles que nos miran con nerviosismo y ternura. Entramos en la mansión encantada de una mente que vive en un lugar apartado de la realidad donde moran con desdén princesas y acróbatas, dominós vivientes, reyes peleones, niñas juguetonas y, sobre todo, muerte. Como banda sonora aparece la musicalidad de los versos egurenianos. «Nocturno» es una sinfonía de sonidos:

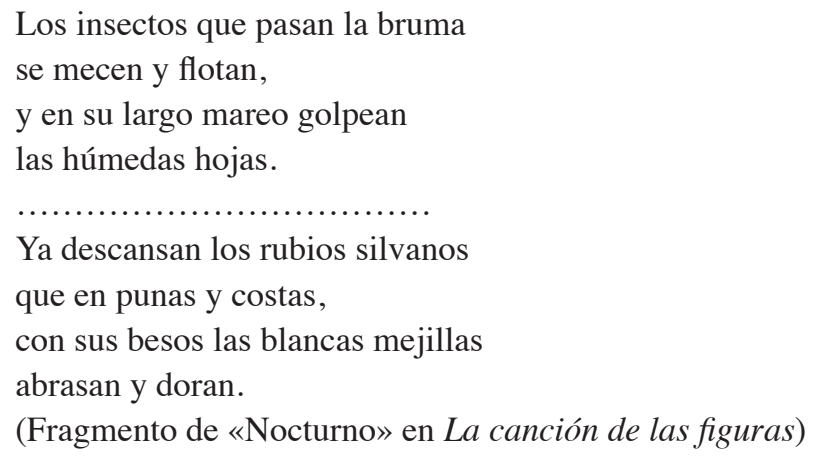

Además de romper con el lenguaje aparatoso rimbombante de Chocano, Eguren trajo también nuevos aires a la poesía ya que el poeta fue más allá del Modernismo gracias a la simplificación poética: «Eguren no usa casi la metáfora -apunta acertadamente Estuardo Núñez-, de puro sencilla que es su expresión y de puro sincera que es su imaginería». ${ }^{13}$ Aunque existe en algún grado, el mundo onírico que rodea la atmósfera egureniana no requiere demasiada complejidad metafórica. El sortilegio se consigue por otros medios. En el escenario, descrito a veces de forma parna-

\footnotetext{
${ }^{10}$ José María Eguren, op .cit., pág. 195.

${ }^{11}$ Íbid.

${ }^{12}$ Íbid.

${ }^{13}$ Estuardo Núñez, Las letras de Francia y el Perú, Lima, UNMSM, 1997, pág. 51.
} 
siana, aparecen figuras extrañas entrelazadas en una historia de ambiente siempre tan trágico como sugestivo. La magia egureniana es compacta. Pocas, poquísimas palabras son necesarias para crear un inmenso panorama, pocas palabras, pero las adecuadas, esas que poseen el valor del embrujo: «El poeta tiene un mundo interior neto, particular, sugestivo, y él se limita a darle expresión escrita y directa. No hay circunloquio posible». ${ }^{14}$ Dice Eguren: «Deseamos la concisión». ${ }^{15}$ Esa concreción integra el mundo imaginario del poeta desde lo más profundo ya que su poesía está fundamentada en imágenes y no en metáforas:

La de Eguren es poesía descriptiva -señala Núñez-, declarativa; pero descriptiva de un reino que se desarrolla en la irrealidad, en la fantasía y que se traduce en imágenes sugestivas. Por eso es fundamentalmente poesía de imágenes y no de metáforas. No precisa mayormente de la metáfora, desde el momento que la sugestión se consigue justamente con la ingenuidad y frescura de lo sencillo, de lo primitivo. Sus imágenes logran una gran intensidad, lo cual es dura prueba sin acudir a la metáfora, que implica otras calidades de materia literaria. ${ }^{16}$

En el poema «El duque» se puede observar lo dicho por Estuardo Núñez. El duque se casa con la hija de Clavo de olor. Los versos describen los momentos anteriores al enlace. En pocas palabras, se arma todo un raro universo particular donde una extraña corte de muñecos genuflexivos espera la llegada del duque para postrarse ante su señor:

Hoy se casa el duque Nuez; viene el chantre, viene el juez y con pendones escarlata florida cabalgata; a la una, a las dos, a las diez; que se casa el Duque primor con la hija de Clavo de Olor. Allí están, con pieles de bisonte, los caballos de Lobo del Monte, y con ceño triunfante, Galo cetrino, Rodolfo montante.

\footnotetext{
${ }^{14}$ Estuardo Núñez, op. cit.,1932, pág. 51.

${ }^{15}$ José María Eguren, op. cit., 1997, pág. 242.

${ }^{16}$ Estuardo Núñez, op. cit.,1932, pág. 53.
} 
Con simplicidad aparente, se relata, de manera concisa, la corte de las figuras rocambolescas. En unos cuantos versos, han aparecido varios personajes fabulescos que habitan en la corte del duque Nuez. Gracias a esta concisión y simplicidad, entramos directos al universo egureniano. El duque Nuez no llega y la novia espera: «Y en la capilla está la bella, / mas no ha venido el duque tras ella». El nerviosismo empieza a hacerse notorio:

\author{
Y hacen fieros ademanes, \\ nobles rojos como alacranes; \\ concentrando sus resuellos \\ grita el más hercúleo de ellos: \\ ¿Quién al gran duque entretiene...; \\ ya el gran cortejo se irrita?
}

El mundo onírico de Eguren estalla en los dos últimos versos: «Pero el duque no viene;.../ se lo ha comido Paquita». El duque era una galleta con forma humana que se suele dar a los niños. Paquita se ha comido al duque. La niña organizó el enlace y realizó las preparaciones, invitó a los muñecos de su universo infantil y ellos tomaron vida propia. A Paquita le entró hambre y acabó comiéndose al novio, el gran duque Nuez. La ironía, la inocencia y la festividad de Eguren se ven expresadas en este agradable poema que no deja de tener el matiz violento y cruel representado en la muerte del personaje principal. Siempre existe un final trágico donde la muerte emerge sin piedad. Otra repetición surge en el mundo onírico del peruano, se trata de la reiteración de un esquema estructural: en primer lugar, el yo poético muestra la puesta en escena de los extraños personajes que pululan en el universo fantasmagórico. En segundo lugar, la escena llega a su punto álgido por medio de la aparición de un suceso trágico. El tercer y último momento se da cuando el protagonista muere o desaparece. Pongamos un ejemplo para observar este fenómeno de forma más clara. Se puede tomar casi al azar un poema porque muchos poseen esta disposición. Se ha elegido «Lied II». Este poema se compone de cuatro estrofas de cuatro versos cada una. En las dos primeras se presenta el ambiente que rodea la aparición del personaje principal que se halla en la tercera:

Y el viento en la marisma entornaba

la canción de Schumann vesperal;

y distante un bajel naufraga

en el insidioso peñascal. 


\begin{abstract}
Y vense las obscuras olas masteleros últimos cubrir, con el amor de las playas solas donde van las aves a morir.
\end{abstract}

El ambiente descrito es desolador y está impregnado de cierta ansiedad. Entonces, al comienzo de la tercera estrofa, aparece la protagonista de la historia: «Y surgió la virgen nacarina / desde el submarino panteón / y con la luz del ocaso declina / y con una lánguida canción». Por último, tras el suceso trágico, el protagonista muere o desaparece. En este caso, la última estrofa nos pone en conocimiento de la muerte de la «virgen nacarina». El esquema no es sino la gran alegoría de Eguren y uno de sus sellos estéticos donde nos habla de la gran tragedia que supone la vida en sí misma: lo inexplicable de la existencia y la inexistencia humana. Y unido a este concepto mortuorio y pesimista nos encontramos con otro elemento procedente del Modernismo que en manos de Eguren toma un cariz encendido de lo más sugerente: la mujer. Recordemos que las mujeres en el Modernismo son idealizadas o convertidas en seres malignos por naturaleza. Como Señala Estuardo Núñez, Eguren expresa en su poesía dos tipos de mujer: la mujer erótica (típica del Modernismo) y la mujer-niña con rasgos modernistas que dulcemente se aleja de este movimiento para formar una pieza importante, se puede decir básica, del imaginario egureniano; nos referimos a la niña moribunda. Veamos, en primer lugar, un ejemplo de la mujer erótica en un fragmento de «La muerta de marfil» poema incluido en Sombra:

\author{
Clara, la niña bullidora, \\ corrió a bañarse en linfa mora, \\ para ir luego a la fiesta \\ de la heredad vecina; \\ ¡Oh!, en la linfa funesta y honda \\ fue a bañarse la virgen blonda; \\ de los amores encendida, \\ la mirada llena de vida...
}

La mujer voluptuosa del Modernismo es seguida al pie de la letra. La rubia maligna se baña con impudor en la fuente del jardín. El lujo sensual espera en la fiesta posterior mientras en su mirada, sedienta de amor, se percibe la maldad.

Donde realmente se da una verdadera innovación es en la representación de la niña-luz. Es una niña (a veces moribunda) que parece haber cruzado el umbral de la muerte para unirse con el poeta en un lazo de extraños nudos. La niña amada 
permanece eternamente infantil, reluciente, rodeada de un halo de inocencia incorruptible. La niña moribunda es un rescoldo de la mujer bella pero enferma de Edgar Allan Poe. Veámosla en el fragmento del poema «La muerta de marfil», incluido en Sombra:

Contemplé, en la mañana,

la tumba de una niña;

en el sauce lloroso gemía tramontana, desolando la amena, brilladora campiña.

Desde el túmulo frío, de verdes oquedades, volaba el pensamiento

hacia la núbil áurea, bella de otras edades, ceñida de contento.

El hecho de que elija una niña da un patetismo muy particular a su poesía. Posiblemente sea la única forma que el poeta posee para describir la angustia que le produce comprobar que el ser humano se enfrenta al fracaso de la muerte perennemente. Quizá la niña no sea sino la representación del alma humana, pura e inocente (por lo menos en un principio) sobre la que se cierne la injusticia de la enfermedad y la muerte. Una de las composiciones más famosas de Eguren titulada «La niña de la lámpara azul» tiene como protagonista a una versión de la niña moribunda, que es la niña llegada del más allá y que, cruzando la frontera de la vida y la muerte, ha vuelto para iluminar al poeta:

En el pasadizo nebuloso cual mágico sueño de Estambul, su perfil presenta destelloso la niña de la lámpara azul.

Ágil y risueña se insinúa, y su llama seductora brilla, tiembla en su cabello la garúa de la playa de la maravilla.

Con voz infantil y melodiosa en fresco aroma de abedul, habla de una vida milagrosa la niña de la lámpara azul. 


\begin{abstract}
Con cálidos ojos de dulzura
y besos de amor matutino,

me ofrece la bella criatura

un mágico y celeste camino.
\end{abstract}

De encantación en un derroche,

hiende leda, vaporoso tul;

y me guía a través de la noche

la niña de la lámpara azul.

(La canción de las figuras)

En el poema aparece una niña que, amorosamente y por la noche (¿es un sueño?), guía al poeta como si se tratara de una nueva Beatriz (la donna angelicata de Dante), inocente, bella, idealizada, casi fantasmagórica; ya no es un ser humano. Dice Estuardo Núñez: «Cuando Eguren desvitaliza a la mujer, cuando la des-organiza, se obtiene entonces el tipo de "la niña", el cual no solo supera el concepto sexual, sino aun el erótico. En realidad, "la niña" no tiene caracteres femeninos, y definitivamente no es mujer».${ }^{17}$ Esta versión de la niña fantasma parece ser la contraposición a la niña muerta o moribunda ya que se trata de un ser vencedor de la muerte, que viene a mostrar un camino de felicidad al yo poético. Puede ser la metamorfosis de la niña moribunda también que, como una crisálida, ha pasado de lo humano a convertirse en el ideal. De todas formas, tanto si se trata de sufrirla o de vencerla, la muerte sigue siendo protagonista de la poesía egureniana:

El ideal de vida tiene algo de muerte -señala Eguren-, se enlaza con la muerte, como principio de nueva existencia. El ideal de la muerte es una aspiración al infinito, al afán de conocer la ciudad nueva espiritual, misteriosa; la metamorfosis del espíritu en la ternura de la luz; el movimiento de ascensión que es el alma misma; el átomo creador diminuto; porque está cerca del principio. ${ }^{18}$

Los modernistas seguían utilizando la imagen de la noche como ya lo hicieron los románticos para mostrar inquietud, sufrimiento y angustia. La predilección de lo nocturno en Eguren no es casual. No se trata ya de mostrar la noche como un lugar desde donde el poeta expresa sus sentimientos de tristeza; para Eguren, la noche simboliza lo misterioso del universo:

\footnotetext{
${ }^{17}$ Estuardo Núñez, op. cit.,1932, pág. 110.

${ }^{18}$ José María Eguren, op .cit., pág. 251.
} 
José María Eguren y la búsqueda de la propia esencia...

La noche es la sombra del día, el principio de la luz, el corolario del teorema ignoto; es la nada tenedora de mundos. Se siente como signo del descanso la beldad del Caos; pero es ferviente e incansable. Se evade el conocimiento; pero si no hubiéramos visto la luz del día y no brillaran los luceros, siempre sabríamos que es una sombra. Su color apaga sus colores, y es poseedora de colorido de todas las cosas que encubre. Vela las cunas de los hombres, guarda las normas antiguas y los recuerdos. ${ }^{19}$

El vate peruano se encuentra fascinado por la noche ya que es el momento del día en que lo ambiguo triunfa, en el que los contornos de los objetos y las personas se diluyen, donde no se acierta a saber de dónde vienen los sonidos que la oscuridad desprende. En el fondo es como la música, la noche difumina la realidad, sugiriendo realidades diferentes a quien la vive:

\author{
¡Alma tristeza, noche!; \\ del boudoir las hojas la plegaria \\ han cantado del amor marchito, \\ gime su desnudez un aria \\ en azul precito, \\ los mochuelos con indiferencia \\ cruzan el camarín, \\ y termina su fosforescencia \\ en el negro jardín.
}

(«Alma tristeza», La canción de las figuras)

En conclusión, se puede decir que Eguren es uno de los poetas más sutiles y lúcidos de Perú. En la obra de Eguren (no demasiado extensa pero sí intensa), se percibe la influencia de la modernidad y de los oropeles rubendarianos. Pero su poesía no se quedó en una mera repetición de la descripción voluptuosa y lujosa de ambientes ostentosos modernistas. Eguren dio un paso más. Con todos los componentes del Modernismo (sobre todo el Simbolismo) Eguren hizo el milagro de crear desde sí mismo un nuevo y desconocido universo. No es el universo modernista de Rubén Darío, y muchísimo menos de Chocano. Entrar en Eguren es hacer una parada en el tiempo y en el espacio. Es volver a la infancia, a veces cruel, a veces maravillosa para recrear lo que fuimos y ya no somos, ese mundo maravilloso de la inocencia salvaje. Resulta interesante conocer las palabras que le dedica Estuardo Núñez (prólogo de Obras Completas), uno de los críticos que con más rigor y entusiasmo ha analizado la literatura peruana:

\footnotetext{
${ }^{19}$ José María Eguren, op .cit., pág. 239.
} 
José María Eguren constituye, hasta su momento, y sin contar a César Vallejo, la más alta cifra de la poesía peruana de todos los tiempos. Tal valoración le alcanza en cuanto a poeta en sí, y también en cuanto constituye el representativo casi único en el Perú, de una tendencia poética moderna, el simbolismo. Clasicistas como Melgar y Olmedo, románticos como Salaverry y Althaus, parnasianos como González Prada, y modernistas como Chocano, no lograron, con todos sus méritos, perfilar en calidad, en coherencia y en intensidad una obra poética semejante a la de Eguren..$^{20}$

\section{Bibliografía}

Anchante. Jim, Naturaleza y función de los símbolos en el poemario Simbólicas de José María Eguren. Lima. Pontificia Universidad Católica de Perú, 2011.

Basadre, Jorge, Equivocaciones. Ensayos sobre literatura penúltima. Lima, La Opinión Nacional, 1928.

Trend, John, «Perú ignoto», en José María Eguren. Aproximaciones y perspectivas, Lima, Universidad del Pacífico, 1977, págs. 45-69.

Chapilliquén, Josué, La crisis sacrifical en la poesía de José María Eguren. Lima, Pontificia Universidad Católica de Perú, 2011.

Eguren, José María, Obras completas. Lima, Ed. Lima, 1997.

Ferrari, Americo, «La función del símbolo en la obra de Eguren», en José María Eguren. Aproximaciones y perspectivas. Lima, Universidad del Pacífico. 1977.

González, José Antonio, «Utopías y nacionalismo cultural en América Latina. La interpretación de Andrés Sabella a la contribución de Mariátegui, Vallejo y Eguren», Estudios Políticos, 40, págs. 120-143, 2012.

Mariátegui, José Carlos, 7 ensayos de la realidad peruana. Lima, Empresa Editora Amauta, 1989.

Núñez, Estuardo, La poesía de Eguren. Lima, Compañía de Impresiones y Publicidad Editores, 1932.

Núñez, Estuardo, Las letras de Francia y el Perú. Lima: UNMSM, 1997.

Silva-Santisteban, Ricardo (Comp.), José María Eguren. Aproximaciones y perspectivas. Lima, Universidad del Pacífico, 1977.

Valles, José, «Hacia una nueva interpretación del poema "Los reyes rojos" de José María Eguren». Anuario de estudios filológicos, Vol. XXXIV, págs. 301-310, 2011.

\footnotetext{
${ }^{20}$ Estuardo Núñez, op.cit., pág. 7.
} 
Valles, José, «Las causas de los Motivos de Eguren. Bases críticas, planteamientos estéticos e ideas sobre la literatura en Motivos de José María Eguren». Acta Literaria. 53, págs. 95-109, 2016.

Zulen, Pedro, «Un neo-simbolismo poético. Apuntaciones sobre José M. Eguren y sus poesías», en José María Eguren. Aproximaciones y perspectivas. Lima, Universidad del Pacífico, 1977. 